patients (30\%) manifested thrombocytopenia and 4 patients $(20 \%)$ manifested anemia.

3. Cardiac symptoms included shortness of breath $(n=18)$, palpitation $(n=6)$, edema of lower extremity $(n=4)$, fatigue $(n=5)$ and/or cough $(n=3)$. All patients were found to have cardiomegaly by echocardiography (UCG) or chest radiography. Left ventricular ejection fraction $(47 \pm 15 \%)$ were decreased. Ventricular wall motion abnormality was found in 5 patients $(25 \%)$ by UCG. 15 patients $(75 \%)$ manifested cardiac arrythmia in electrocardiogram, with frequent premature ventricular contractions were the most common $(n=10,50 \%)$. Myocardial injury was found in 14 patients $(70 \%)$ by electrocardiogram. Myocarditis was found in 7 patients $(35 \%)$ by myocardial enzyme assay.

4. Nine patients $(45 \%)$ died, the causes of death were heart failure $(n=4$, $45 \%)$, sudden death $(n=3,33 \%)$ and ventricular tachycardia $(n=2,22 \%) .5$ patients $(55.6 \%)$ died within 1 month after the onset of cardiac symptoms. 3 patients died within 2 month, and one patient with implantable cardioversion defibrillation (ICD) died 2 years after ICD implanted. Ten patients survived in a mean 6 (1 10) years follow-up.

5. Six patients $(67 \%)$ manifested thrombocytopenia and 4 patients $(44 \%)$ manifested anemia in the death group. However, only one patient $(9.1 \%)$ in survival group manifested thrombocytopenia $(\mathrm{p}=0.007)$ and anemia $(p=0.069)$. There were more organs and systems involved in the death group, compared to the survival group ( $4 \pm 2$ vs $2 \pm 1, p=0.044)$. 4 patients had SRC in death group, while 2 patients had SRC in survival group. 6 patients had pulmonary fibrosis in death group, while 5 patients in survival group (Table 1).

Table 1. Comparison between the death group and the survival group in Systemic Sclerosis cardiomyopathy patients.

\begin{tabular}{lccc}
\hline & $\begin{array}{c}\text { Death } \\
\text { group } \\
(\mathrm{n}=9)\end{array}$ & $\begin{array}{c}\text { Survival } \\
\text { group } \\
(\mathrm{n}=11)\end{array}$ & $\mathrm{p}$ \\
\hline Thrombocytopenia, $\mathrm{n}(\%)$ & $6(66.7)$ & $1(9.1)$ & $\mathbf{0 . 0 0 7}$ \\
Anemia, $\mathrm{n}(\%)$ & $4(44.4)$ & $1(9.1)$ & 0.069 \\
Pulmonary fibrosis, $\mathrm{n}(\%)$ & $6(66.7)$ & $5(45.5)$ & 0.343 \\
Pulmonary arterial hypertension, $\mathrm{n}(\%)$ & $3(33.3)$ & $4(36.4)$ & 0.888 \\
Scleroderma renal crisis, $\mathrm{n}(\%)$ & $4(44.4)$ & $2(18.2)$ & 0.202 \\
Esophageal involvement, $\mathrm{n}(\%)$ & $3(33.3)$ & $2(18.2)$ & 0.436 \\
Anti-SCL 70 positive, $\mathrm{n}(\%)$ & $5(55.6)$ & $5(50)$ & 0.653 \\
Myocarditis, $\mathrm{n}(\%)$ & $4(44.4)$ & $3(27.3)$ & 0.423 \\
Numbers of organ involved, mean & $4(2)$ & $2(1)$ & $\mathbf{0 . 0 4 4}$ \\
(SD) & & & \\
\hline
\end{tabular}

Conclusion: Thrombocytopenia and multi-organ involvement might be poor prognostic factors for patients of SSc-cardiomyopathy.

Disclosure of Interests: None declared

DOI: 10.1136/annrheumdis-2019-eular.4082

\section{FRI0319 ESOPHAGEAL EROSIONS PREDICT PROGRESSION OF LUNG DISEASE IN PATIENTS WITH SYSTEMIC SCLEROSIS}

Enrico De Lorenzis ${ }^{1}$, Gerlando Natalello ${ }^{1}$, Laura Gigante ${ }^{1}$, Lucrezia Verardi ${ }^{1}$, Umberto La Porta ${ }^{1}$, Giovanni Battista Canestrari ${ }^{1}$, Ludovica Berardini ${ }^{2}$, Silvia Laura Bosello ${ }^{3}$, Elisa Gremese ${ }^{1,3} .{ }^{1}$ Catholic University of the Sacred Heart, Institute of Rheumatology, Rome, Italy, ${ }^{2}$ Fondazione Policlinico Universitario A. Gemelli IRCCS, Department of Respiratory Medicine, Rome, Italy; ${ }^{3}$ Fondazione Policlinico Universitario A. Gemelli IRCCS, Department of Rheumatology, Rome, Italy

Background: Interstitial lung d isease (ILD) is the leading cause of death in Systemic Sclerosis (SSc) but its pathogenesis is not fully understood. Esophageal disease is common in SSc and micro aspiration of both acid and non-acid gastroesophageal reflux could be involved in the pathogenesis of ILD. Esophagogastroduodenoscopy (EGD) is an essential tool to evaluate disease severity of upper gastrointestinal tract involvement in SSc.

Objectives: The objective of the present study is to assess the role of EGD in predicting pulmonary functional deterioration in SSc patients.

Methods: One hundred and fifty patients with SSc and suspected esophageal involvement underwent EGD. Pulmonary function tests were performed at baseline and after a 36-months follow-up. Patients were characterized for disease phenotype, BMI, smoking exposure and medication history. A significant ILD progression was defined as a relative decline $>=10 \%$ of FVC or a concomitant decline $>=5 \%$ of FVC and $>=15 \%$ of DLCO.

Results: One hundred and thirty-six patients (90.5\%) were female with a mean age of $55.6 \pm 13.8$ years and $12.1 \%$ were active smokers. Fifty patients (33.3\%) had a diffuse cutaneous disease; $37.4 \%$ and $40.8 \%$ were positive for anti-centromere and anti-Scl70 antibodies respectively. The mean disease duration from the first non-Raynaud symptom was 5.9 \pm 6.7 years. Sixty-one patients $(40.8 \%)$ showed EGD signs of reflux esophagitis. Among them, $31.3 \%$ had an erosive form $(9.5 \%$ grade $A$ $15.6 \%$ grade $B, 4.8 \%$ grade $C$ and $1.4 \%$ grade $D$ according to Los Angeles classification). At the baseline, $23.1 \%$ of the patients had a FVC $<=80 \%$ and $45.6 \%$ had a DLCO $<=50 \%$. Patients with erosive esophagitis did not differ in terms of sex, age, duration and disease variant, positivity for anti-centromere, skin score values, FVC and DLCO at baseline compared to patients without erosions, but had a lower prevalence of anti-Scl70 (28.3 vs 52.5\%, $\mathrm{p}=0.005)$ and active smoking (20.0 vs $8.4 \%, p=0.05)$. At follow-up, patients with esophageal erosions showed a greater relative decrease in FVC $(3.4 \% \pm 9.3 \%$ vs $1.7 \% \pm 12.0 \% ; p=0.013)$ without significant differences in the DLCO change. Overall, $11.0 \%$ of patients presented pulmonary disease progression. The presence of esophageal erosions was associated with a significantly greater risk of lung disease progression (OR 5.3, 95\% Cl 1.7-16.8, $\mathrm{p}=0.004$ ) after paired correction for sex, age, duration of disease, auto-antibodies, skin involvement variant, baseline FVC and DLCO, smoke exposure and therapy with immunosuppressants, proton pump inhibitors, prokinetics, antiplatelet agents and prostanoids.

Conclusion: SSc patients with erosive esophagitis present a higher risk of progression of interstitial lung disease. This evidence supports a role of micro-aspiration of gastric contents in the development of inflammation and fibrosis of the airways.

Disclosure of Interests: Enrico De Lorenzis: None declared, Gerlando Natalello: None declared, Laura Gigante: None declared, Lucrezia Verardi None declared, Umberto La Porta: None declared, Giovanni Battista Canestrari: None declared, Ludovica Berardini: None declared, Silvia Laura Bosello: None declared, Elisa Gremese Consultant for: AbbVie, BMS, Celgene, Janssen, Lilly, MSD, Novartis, Sanofi, UCB, Roche, and Pfizer, Speakers bureau: BMS, Speakers bureau: Roche, Speakers bureau: AbbVie, BMS, Celgene, Janssen, Lilly, MSD, Novartis, Sanofi, UCB, Roche, and Pfizer

DOI: 10.1136/annrheumdis-2019-eular.6401

\section{FRI0320 CN-1A AUTOANTIBODIES ARE SPECIFIC FOR SPORADIC INCLUSION BODY MYOSITIS}

Louise Pyndt Diederichsen ${ }^{1,2}$, Sine Søndergaard Korsholm ${ }^{1}$, Line

Vinderslev Iversen ${ }^{3}$, Christoffer Tandrup Nielsen ${ }^{2}$, Marie-Louise

From Hermansen ${ }^{2}$, Søren Jacobsen ${ }^{2}$, Nanna Witting ${ }^{4}$, Markus E. Krogager ${ }^{4}$,

Tina Friis ${ }^{5}$. ${ }^{1}$ Odense University Hospital, Department of Rheumatology, 5000 Odense, Denmark; ${ }^{2}$ Rigshospitalet, Department of Rheumatology, DK-2100 Copenhagen, Denmark; ${ }^{3}$ Bispebjerg Hospital, Department of Dermatology, DK2400 København NV, Denmark; ${ }^{4}$ Rigshospitalet, Department of Neurology, Copenhagen, Denmark; ${ }^{5}$ Statens Serum Institut, Department of Autoimmunology and Biomarkers, DK-2300 Copenhagen S, Denmark

Background: Sporadic inclusion body myositis (sIBM) is a subgroup of the idiopathic inflammatory myopathies (IIMs) and is characterized by both degenerative and autoimmune features. Unlike other IIMs, myositisspecific autoantibodies had not been found in sIBM patients until recently.

Objectives: We aimed to establish the prevalence and clinical associations of anti-cN-1A in a large Danish cohort with connective tissue diseases (CTD).

Methods: In a cross-sectional study design, a total of 568 participants (183 IIMs (55 slBM, 128 non-sIBM: dermatomyositis (DM), polymyositis (PM), immune-mediated necrotizing myopathy (IMNM)), 164 systemic lupus erythematosus (SLE), 121 systemic sclerosis (SSc), and 100 blood donors (BD)) were tested for the presence of: a) $\mathrm{cN}-1 \mathrm{~A}$ autoantibodies using a commercial Anti-cN-1A ELISA and b) myositis specific and associated autoantibodies (anti-Jo-1, anti-PL-7, anti-PL-12, anti-OJ, anti-EJ, anti-SRP, anti-Mi-2 $\alpha / \beta$, anti-MDA5, anti-TIF $1 \gamma$, anti-NPX2, anti-SAE1, antiPM-Scl75, anti-PM-Scl100, anti-Ro52, anti-Ku) using a commercial lineblot kit. The patients were classified according to the ACR classification criteria for IIMs (2017), SLE (1997) and SSc (1980), respectively. Clinical features were compared between anti-cN-1A positive and anti-cN-1A negative sIBM patients using two-sample t-test and Mann-Whitney test for continuous normally and non-normally distributed data and Chi-square test for categorical data, as appropriate.

Results: $\mathrm{cN}-1 \mathrm{~A}$ antibodies were predominantly found in IIM patients. In the sIBM cohort, 24 patients $(43.6 \%)$ were anti-cN-1A positive vs. 25 $(19.5 \%)$ in the non-sIBM myositis cohort and $17(10 \%)$ in the SLE cohort. None of the participants in the SSc or the BD cohorts had 
presence of anti-cN-1A. Anti-cN-1A positivity had a sensitivity of $43.6 \%$ and a specificity of $91.8 \%$ for sIBM. The positive and negative predictive values were $36.4 \%$ and $93.8 \%$, respectively.

There was no significant difference in gender, age at study entry, age at symptom onset, duration of symptoms or max creatine kinase (CK) levels during disease course between the anti-cN-1A positive and negative slBM patients. Dysphagia was present in $19(79 \%)$ of the anti-cN-1A positive and in $17(55 \%)$ of the anti-cN-1A negative sIBM patients $(P=0.06)$.

Conclusion: Antibodies against $\mathrm{cN}-1 \mathrm{~A}$ are the first and so far the only serological marker for sIBM. Our data showed that $\mathrm{cN}-1 \mathrm{~A}$ autoantibodies are specific for sIBM and further corroborate the potential diagnostic role of $\mathrm{cN}-1 \mathrm{~A}$ autoantibodies in this distinct subgroup of myositis.

Disclosure of Interests: Louise Pyndt Diederichsen: None declared, Sine Søndergaard Korsholm: None declared, Line Vinderslev Iversen: None declared, Christoffer Tandrup Nielsen: None declared, Marie-Louise From Hermansen: None declared, Søren Jacobsen: None declared, Nanna Witting: None declared, Markus E. Krogager: None declared, Tina Friis Grant/research support from: Anti cN-1A ELISA kits and EUROLINE Autoimmune Inflammatory Myopathies 16 AG kits have been provided for a project free of charge from Euroimmun.

DOI: 10.1136/annrheumdis-2019-eular.7264

\section{FRI0321 PERFORMANCE OF DIFFERENT PULMONARY HYPERTENSION SCREENING ALGORITHMS IN PATIENTS WITH SYSTEMIC SCLEROSIS PATIENTS}

Mustafa Erdogan ${ }^{1}$, Burcak Kilickiran Avci $^{2}$, Yagmur Ersoy $^{3}$, Cansu Ebren $^{2}$ Zeki Ongen ${ }^{2}$, Gul Ongen ${ }^{4}$, Vedat Hamuryudan ${ }^{1}$, Gulen Hatemi ${ }^{1} .{ }^{1}$ Istanbul University -Cerrahpasa Medical Faculty, Internal Medicine, Division of Rheumatology, Istanbul, Turkey, ${ }^{2}$ Istanbul University -Cerrahpasa Medical Faculty, Department of Cardiology, Istanbul, Turkey, ${ }^{3}$ Istanbul University -Cerrahpasa Medical Faculty, Istanbul, Turkey; ${ }^{4}$ Istanbul University -Cerrahpasa Medical Faculty, Department of Pulmonary Diseases, Istanbul, Turkey

Background: Pulmonary hypertension $(\mathrm{PH})$ is an important cause of morbidity and mortality in patients with systemic sclerosis (SSc). Different screening algorithms have been proposed for identifying patients who have a high probability of $\mathrm{PH}$ and require right heart catheterization $(\mathrm{RHC})$, which is the gold standard for diagnosing $\mathrm{PH}$.

Objectives: To compare the performance of $\mathrm{PH}$ screening algorithms in our patients with SSc.

Methods: Forty-eight consecutive patients, fulfilling ACR/EULAR 2013 SSC criteria, were screened for PH using the, 2015 ESC/ERS, DETECT and ASIG algorithms. Pulmonary function tests (PFT), diffusing capacity of the lung for carbon monoxide (DLCO), trans-thoracic echocardiography, serum NT-proBNP, uric acid assay and high-resolution computed tomography (HRCT) were performed as needed. Patients with known $\mathrm{PH}$, severe interstitial lung disease and severe left ventricular dysfunction were not included. $\mathrm{RHC}$ was performed in all patients with positive screening according to any one of the screening algorithms. Patients with $\mathrm{PH}$ were classified according to the updated $\mathrm{PH}$ classification criteria. Sensitivity and specificity of the 3 screening algorithms were evaluated according to the established cut-off value of $25 \mathrm{mmHg}$ for mean systolic pulmonary artery pressure and for the recently proposed cut-off value of $20 \mathrm{mmHg}$ Results: Among the 48 SSc patients, 15 were excluded due to already diagnosed $\mathrm{PH}(n=4)$, left ventricular dysfunction $(n=4)$, no measurable tricuspid regurgitation velocity (TRV) $(n=5)$ and coexisting lung cancer $(n=2)$. Among the remaining 34 patients, 16 required $\mathrm{RHC}$ according to at least one of the screening algorithms. Demographic and clinical features of remaining 34 patients were summarized in Table 1. Number of patients who had suspected pulmonary hypertension and required $\mathrm{RHC}$ according to ESC/ERS 2015, DETECT and ASIG were 8 (\%25), 9 (\% $27)$, and $13(\% 41)$ respectively (Figure 1). Among the 14 who had RHC, $\mathrm{PH}$ was present in 3 patients according to the 25-mmHg cut-off (Group1 in 1, Group 2 in 1, Group 3 in 1) and in 8 patients according to the 20-mmHg cut-off (Group 1 in 5, Group 2 in 2, Group 3 in 1). The sensitivity and specificity of each algorithm is presented in Table 2. Sensitivity was similar at $100 \%$ for the 3 algorithms, but the ESC/ERS algorithm had better specificity, when $\mathrm{PH}$ was diagnosed with the $25-\mathrm{mmHg}$ cut-off. For the $20-\mathrm{mmHg}$ cut-off, both the sensitivity and the specificity were better with the ESC/ERS algorithm.

Conclusion: The ESC/ERS algorithm seems to have a better performance for detecting $\mathrm{PH}$ in patients with SSc. A limitation of this study was that $\mathrm{RHC}$ was not performed in patients who did not fulfill criteria according to any of the screening algorithms. The sensitivities may be lower than what we propose if there are patients with $\mathrm{PH}$ who are asymptomatic and not captured with any of the algorithms.

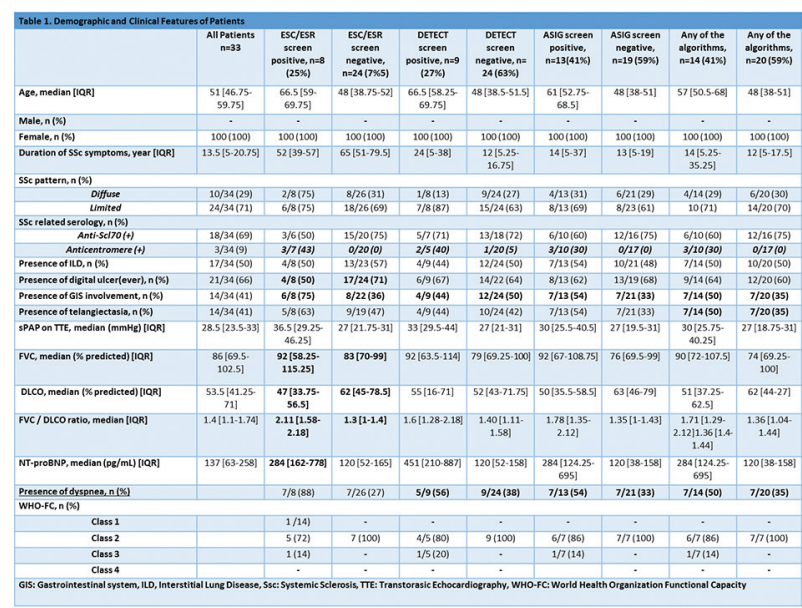

Disclosure of Interests: Mustafa Erdogan: None declared, Burcak Kilickiran Avci: None declared, Yagmur Ersoy: None declared, Cansu Ebren: None declared, Zeki Ongen: None declared, Gul Ongen: None declared Vedat Hamuryudan Consultant for: Abbvie, Amgen, BMS, Jansen, MSD Pfizer, UCB, Speakers bureau: Abbvie, Amgen, BMS, Jansen, MSD Pfizer, UCB, Gulen Hatemi Consultant for: Abbvie, Amgen, BMS, Janssen, MSD, Pfizer, UCB, Speakers bureau: Abbvie, Amgen, BMS, Jansen, MSD, Pfizer, UCB,

DOI: 10.1136/annrheumdis-2019-eular.2662

\section{FRI0322 AUTOANTIBODIES PROFILE INFLUENCE ON SYSTEMIC SCLEROSIS INTERSTITIAL LUNG DISEASE. A TERTIARY SPANISH HOSPITAL EXPERIENCE}

Antía García Fernández ${ }^{1}$, Iván del Bosque Granero ${ }^{1}$, Laura Calvo Sanz ${ }^{1}$, Nicolás Almeida Arostegui ${ }^{2}$, Luis Gorospe Sarasúa ${ }^{2}$, Carlos De la Puente Bujidos ${ }^{1}$

${ }^{1}$ Ramón y Cajal University Hospital, Rheumatology, Madrid, Spain; ${ }^{2}$ Ramón y Cajal University Hospital, Radiology, Madrid, Spain

Background: Systemic Sclerosis (SSc) is a rare and heterogeneous connective tissue disease (CTD) characterized by skin fibrosis, vasculopathy/vascular damage and potential visceral impairment. Interstitial lung disease (ILD) constitutes the leading cause of mortality and requires close periodical assessment and follow-up. Diffuse cutaneous sclerosis and specific autoantibody profile (anti SCL70 anti Th/To, Anti U3 RNP and anti PmScl) are considered ILD development risk factors. In contrast, positivity to anticentromere has been considered as a protec tive factor to develop a clinical significant ILD.

Objectives: To assess ILD frequency and severity (extension and func tional impairment) in SSc patients, analyzing the association with the different autoantibodies.

Methods: Retrospective, descriptive study of patients meeting EULAR/ACR 2013 SSc criteria and had a HRTC performed at a tertiary Spanish hospital from 1975 to 2018. One hundred and eight patients were included HRCTs were graded by two radiologists according to Goh et al semiquantitative score. Three groups were established according to the pres ence of different autoantibodies: anticentromere (ACA), antitopoisomerase (ATA), and positivity to other ANAs (nucleolar pattern and other specificities).

Results: Clinical and laboratory characteristics are presented in table 1 . Thirty-three patients had pulmonary involvement, 6 were ACA+, 18 ATA+ and 9 had other ANA specificities. The probability of not having pulmonary involvement among $\mathrm{ACA}+$ and of having pulmonary involvement among ATA + showed statistic significance $(p<0.001$ and $p<0.001)$. Usual intestinal Pneumonia (UIP) was the most frequently reported pattern (6 patients), followed by Non-Specific Interstitial Pneumonia (NSIP 11 patients); Six patients did not meet the radiological criteria for neither UIP or NSIP. No statistical significant difference was found among radio logical pattern and autoantibody profile. Regarding extension: 15 patients 